\title{
Productions and Perceptions of Apologies: Intercultural Comparisons
}

\author{
Xin Wang ${ }^{1}$ \\ ${ }^{1}$ College of Education, Northern Arizona University, Arizona, USA \\ Correspondence: Xin Wang, College of Education, Northern Arizona University, Arizona, USA. Tel: \\ $1-928-380-4608$.
}

Received: May 10, 2017

Accepted: May 26, 2017

Online Published: June 10, 2017

doi:10.20849/aes.v2i2.160

URL: https://doi.org/10.20849/aes.v2i2.160

\begin{abstract}
The productions and perceptions of apologies vary from one language to another in terms of linguistic realization patterns, strategic preferences, and evaluative opinions. Accordingly, these variations motivate the investigation of apology use and its perceptions in different languages. By comparing productions and perceptions of apologies among college students who speak Arabic, Russian, English and Chinese languages, the current study reports on the students' various strategic preferences (i.e., explicit or direct apology strategies, less explicit or indirect apology strategies and strategy combinations) and their diverging tendencies to evaluate the $\mathrm{im} /$ politeness of apologies. The results have confirmed that although the concept of apology is universal, its applications and interpretations can be divergent across various language groups and within each language group. These observed discrepancies can be attributed to sociocultural influences (e.g., face need concerns and culturally-specific perceptions of sincerity), gender-related differences (e.g., explicit and indirect apology strategies used more frequently by females than males) and situational characteristics (e.g., positive vs. negative face threatened situations, and in-group vs. out-group memberships). In addition, the author believes that this synthesis study will provide certain implications for ESL/EFL teaching and learning by enhancing the awareness of intercultural communicators to better make inferences from the effects of the three responsible factors on their use of apologies.
\end{abstract}

Keywords: apology strategies, perceptions, sociocultural influences, gender differences, situational characteristics

\section{Introduction}

An apology is defined as a speech act which is intended to provide support for the hearer who was actually or potentially malaffected by a violation (as cited in Bataineh \& Bataineh, 2008). When an apology is offered, the apologizer expresses his/her willingness to humiliate him/herself to repair a harmed social relationship by saving the victim's face. The productions and perceptions of apologies are not only related to such factors as familiarity with a victim and intensity of the offense, but also have much bearing on subtle influences that derive from particular sociocultural contexts, gender-related differences, and situational characteristics. To account for the commonalities and disparities of apology use in different languages such as Arabic, Russian, English and Chinese, the present synthesis study discusses the effects of sociocultural contexts, gender-related differences and situational variations on the linguistic realization of apologies and the evaluation of apology use.

\section{Linguistic Realizations of Apologies}

The linguistic forms of different apology strategies are introduced before we locate the responsible factors for apology use and its perceptions. To effectively repair a potentially harmed relationship, a speaker needs to adjust his or her apology strategies by using different linguistic forms. Basically, apology strategies fall into three categories: explicit or direct apology strategies, less explicit or indirect apology strategies, and strategy combinations (Bataineh \& Bataineh 2008; Ogiermann, 2008). As for explicit or direct apology strategies, their linguistic forms can be realized by using "one expression of apology" with and without certain intensifier(s). For example, "I am sorry" does not have an intensifier, while "I am so/really/terribly/very sorry" has an intensifier "so", "really", "terribly" and "very". "One expression of apology" also includes "forgive me", "excuse me", "my apologies" and "I apologize for ...". By investigating explicit or direct apology strategies, Bataineh \& Bataineh (2008) found that the American participants (i.e., 100 American college undergraduates) used more direct formulaic expressions of apologies than their Jordanian counterparts (i.e., 100 Jordanian college undergraduates). 
Americans resorted to 655 times and Jordanians 520 times of explicit apology strategies when they were asked to respond in a written form to ten situations warranting apologies in their separate native language. Regarding the choice of specific linguistic forms, Oigermann's study (2008) used a Discourse Completion Test (DCT) to elicit written responses from their 100 Russian college students and 100 British college students to ten apology-warranting scenarios. The findings revealed that the British English speakers preferred "I am sorry" (i.e., 336 occurrences out of 635) as a ritualized expression of apology, while the Russian speakers preferred "izvini-te", a Russian equivalent to "forgive me" in English, as their frequently employed linguistic pattern (i.e., 404 occurrences out of 529).

For less explicit or indirect apology strategies, the linguistic realizations vary depending on the contents of an offense. A speaker can offer a variety of accounts in different linguistic forms to explain an offense and to express his or her willingness to take on responsibility (as cited in Ogiermann, 2008). These accounts are related to assessment of responsibility by the apologizer. If the apologizer assesses the responsibility positively, he or she is willing to face up with the offense without blaming others or acting innocently. This often leads to such linguistic manifestations as "It was totally my fault", or "I am completely useless" to connote sincerity and readiness to accept responsibility. If the offense is assessed negatively by the offender, he or she would use phrases or expressions implying their unwillingness to assume the responsibility, which might somewhat prevent the offender from providing compensation to remedy the breach of etiquette. For example, by saying that "I did return them on time, though", the speaker attempts to find an excuse to shun away from their responsibility. As in Bataineh \& Bataineh's (2008) study, Jordanian undergraduates used more accounts (i.e., 364 occurrences) to explain an offensive situation than their American counterparts (i.e., 304 occurrences).

Apart from accounts, indirect apology strategies also encompass "offer of repair", "promise of forbearance", and "concern for hearer". Due to variations in contextualized offenses, linguistic realizations of these indirect apology strategies are situationally specific. As in Bataineh \& Bataineh's (2008) study, the Jordanian undergraduates employed far less frequently the strategy of "offer of repair" (i.e., 98 occurrences) than their American participants (i.e., 221 occurrences). The American participants are more inclined to express "Let us reschedule" and "I will pick up the books then", while their Jordanian counterparts sometimes failed to express their intention to compensate for an offense. On the other hand, there is a high degree of convergence in the strategy of "offer of repair" among the 100 British college students and their Russian counterparts since the two groups of participants used a similar amount of this strategy (i.e., 365 occurrences for British students and 381 occurrences for their Russian counterparts).

Moreover, the manifestations of the strategy of "promise of forbearance" are often linked to some formulaic expressions such as "It won't happen again", "this is the last time I will be late...", or "I won't do this again, I promise". Interestingly, the British participants used routinized formulae as frequently as their Russian counterparts (i.e., 33 occurrences for each group of participants) (Ogiermann, 2008). However, the American participants in Bataineh \& Bataineh's study (2008) were more inclined to appeal to formulaic expressions than their Jordanian counterparts since Jordanian participants used 18 times fewer of routinized phrases and expressions in Arabic to express their forbearance than their American counterparts in English.

For the indirect apology strategy of "concern for hearer", the Russian undergraduates formulated individually different expressions aimed at ascertaining that the victim was really okay and asking how the victim felt, which might indicate that Russians are more attentive to the contextual features of the offense proper (Ogiermann, 2008). Similarly, the Jordanian respondents more frequently used such unified expression as "Don't be angry" in Arabic to appease the victim (Bataineh \& Bataineh, 2008).

Even though direct and indirect apology strategies can be used discretely according to speakers' intention, they can also be used to form different strategy combinations. It is recognized that an apology has "a speech act set which consists of a number of semantic formulas" (as cited in Wolfson, 1989) and the studies on apology strategy combinations are capable of reflecting certain linguistic patterns to follow different semantic sequences. In light of the speaker's evaluation of the severity of the offense and also the social distance and/or the status of the "victim", native speakers of English often choose highly patterned apology forms. For example, "one expression of apology" is often used before indirect apology strategies, which helps express their willingness to take on responsibility, or to make up for the loss, or to promise forbearance. In the study by Ogiermann (2008), the utterances of "one expression of apology", "acceptance of responsibility" and "offer of repair" in a sequential order were used more often in Russian (i.e., 656 occurrences out of 800) than in English (i.e., 588 occurrences out of 800). The Russians preferred "one expression of apology" without any intensifier(s) which was followed by "expression of responsibility", whereas their British counterparts drew heavily on "one expression of apology" coupled with some intensifier(s) but without readiness to assume their responsibility. 


\section{Perceptions of Apologies}

Most studies of apologies so far have focused on productions of apologies, especially their linguistic realization patterns from the speakers' perspective. However, since an apology is interactionally achieved, and can be counted as an apology only if it is both framed as an apology by the speaker and interpreted as an apology by the recipient (as cited in Chang \& Haugh, 2011). How apologies are perceived as appropriate or inappropriate is an empirical question addressing the significance of understanding the apology use in a situated discourse.

In Chang and Haugh's study (2011), they explored the intercultural perceptions of apologies concerning the variations in evaluating politeness and impoliteness of apology strategies. 25 Australians and 25 Taiwanese college undergraduates were asked to evaluate an intercultural apology which was recorded from a naturally occurring 2-minute conversation in English between an Australian and a Taiwanese. Specifically, the participants were asked to assess the im/politeness of apologies offered in the conversation by the Australian in the form of 5-point rating scale. The interpretations of the im/politeness of apologies were diverged between these two groups of participants, with 8 out of 25 Australians rating the apology as impolite but 20 out of 25 Taiwanese rating it as impolite. Park and Guan's study (2006) also adopted the five-point rating scale to explore the intercultural differences of participants' perceptions of apologies in terms of face need concerns. 183 American university undergraduates and 134 Chinese university undergraduates filled out a 22 -item questionnaire as to how they perceived the two situations depicted in the vignettes (i.e., a negative face threatened situation vs. a positive face threatened situation).

To further locate the situational effects, the relationship between the offender and the victim is also taken into account. This study (Park \& Guan, 2006) considered in-group and out-group memberships as situational variants that may influence the participants' perceptions of their intention to apologize. In-group members include friends, family members, and colleagues, whereas out-group members are strangers or opponents whose well-being is of little concern or can even clash with that of in-group members (Park \& Guan, 2006). Based on the research findings, American and Chinese participants showed inconsistency in their perceptions of their intentions to apologize. Particularly, Chinese participants (i.e., $\mathrm{M}=3.39, \mathrm{SD}=1.02$ ) were concerned more about the offended person's positive face compared to American participants (i.e., $\mathrm{M}=2.87, \mathrm{SD}=1.22$ ). However, American participants (i.e., $\mathrm{M}=4.70, \mathrm{SD}=0.73$ ) had a higher regard for the offended person's negative face than did Chinese participants (i.e., $\mathrm{M}=4.34, \mathrm{SD}=0.51$ ). Considering the relationship variable in either a positive or negative face threatened situation, the participants in both language groups perceived their intention to apologize as more constrained by the offended person's negative face than by in-group or out-group memberships since both American and Chinese participants' perceptions of their willingness to apologize did not differ significantly for a friend (i.e., $4.47, \mathrm{SD}=0.68$ ) or a stranger (i.e., $4.46, \mathrm{SD}=0.63$ ) when the victim's negative face was threatened. By contrast, their perceptions of intentions to apologize were stronger for a friend (i.e., M. 3.25, SD $=1.22$ ) than a stranger (i.e., $\mathrm{M}=2.96, \mathrm{SD}=1.11$ ) if the victim's positive face was threatened.

\section{Responsible Factors of Apologies}

All the consulted studies exhibit variability in productions and perceptions of apologies across different language groups. Such variability triggers further reflections on the potential reasons implied in apology strategies and their evaluations, which are discussed in the following three dimensions identified as sociocultural influences, gender-related differences and situational characteristics.

\subsection{Sociocultural Influences}

The differences in apology strategies in Arabic, English, Russian and Chinese languages can be explained by certain sociocultural factors. For example, due to the Islamic culture, Jordanians are ready to cite proverbs and sayings as part of their accounts from the holy Quran to mitigate a victim's anger. In doing so, the victim can sympathize with the apologizer more easily and understand how sincere the apologizer is in his or her apologies and tension before the offer can be eased (Bataineh \& Bataineh, 2008). This religious element is also reflected in apology use by Russians. Russian people use the formulaic expression "prosti-te" to apologize for more serious, even unpardonable offense and "izvinit-te" to address less severe breach of etiquette and they are both associated with religious contexts and forgiving sins (Ogiermann, 2008).

As an important sociocultural variable, face need concerns can also explain marked linguistic realization patterns across British and Russian cultures and help understand perceptions of apologies between American and Chinese cultures. Since apology plays a significant role in protecting and restoring the face of an offender, the face of a victim, or both (as cited in Ogiermann 2008), an offender normally takes into account face need concerns for both parties. How the apologizer views negative and positive faces for the victim has potential influence on his or her apology strategy use. It is argued that Russians prefer to protect the positive face of the offended, while 
British people tend to protect the negative face of the victim. As seen from the study by Ogiermann (2008), Russian respondents used "izvinit-te", an Russian equivalent of "forgive me", as a conventionalized expression to explicitly request for forgiveness from the victim, while British people used more frequently "I'm sorry" or "I am really or so sorry" as a formulaic expression with some intensifier(s) to show their regret. By requesting forgiveness, a Russian offender risks embarrassing the negative face of a victim since the offender places herself or himself at the victim's mercy or impose his or her request on the victim, but this request saves the victim's positive face by denoting the guilt in which the offender admits his or her own fault and is ready to assume responsibility (Ogiermann, 2008). On the other hand, British people regard "I'm sorry" and "I am really or so sorry" as routinized expressions to offer apologies and express regret but these linguistic forms help address the negative face concerns of both parties without explicit requests for forgiveness.

Apart from sociocultural effects on productions of apologies, some research has attested to the influence of sociocultural differences on perceptions of apologies (Chang \& Haugh, 2011; Park \& Guan, 2006). Due to the differences in their sociocultural backgrounds, the Australian and Chinese respondents have different interpretations regarding the importance of sincerity in evaluating the im/politeness of apologies. For Australians, perceptions of sincerity in apologies can be understood as a way of being attentive to and showing interest in the hearer or victim (Chang \& Haugh, 2011). To put it differently, they informally show their personal stance in interactions and to express their friendliness to the hearer, which is accordingly considered as a polite and appropriate manner in the Australian style of communication. As in the study of Chang and Haugh (2011), a number of Australian English speakers perceived the apology in the recorded naturally occurring conversation as genuine and polite (e.g., "I really apologize for not getting back to you the other day but we couldn't make it. So you've been good? So is your mom alright?"). The strategic sequence of the speech act of apology indicates that the Australian speaker used more "concerns for the hearer" in this strategic combination. By showing his attentiveness to the Chinese hearer's well-being, the Australian speaker attempted to invoke solidarity with the hearer and index the claim of an in-group membership. Consequently, the Australian speaker's apology was motivated by projecting friendliness and familiarity with the hearer.

In light of the aforementioned analysis, the majority of the Australian raters evaluated the Australian speaker's apology as "not impolite", while most of the Chinese participants perceived this apology as "impolite. Such strikingly different perceptions indicated that the Chinese raters completely failed to acknowledge friendliness and attentiveness that the Australian speaker had tried to convey. Instead, the Chinese speakers considered that friendliness had nothing to do with politeness and appropriateness in apologies. In Chinese conventional evaluative system, the sincerity in apologies needs to be reflected in a sequential order with repetitive uses of apologetic expressions. Usually, an offer of apology is followed by expressions of gratitude with a final note of repetition of apology. In order to show their sincerity, individuals need to express their willingness to apologize so that the recipient of the speech act can be facilitated to seek confirmations from the apologizer's genuine intention (Chang \& Haugh, 2011).

\subsection{Gender-Related Differences}

It is empirically supported that women apologize more often than men do (as cited in Bataineh \& Bataineh, 2008). The gender-related effects on strategic choice to apologize were obvious regarding explicit apology strategies. American females were reported to use "one expression of apology" such as "my apologies", "sorry", "excuse me" "forgive me" or "pardon me" more frequently than American males (i.e., 51 occurrences more). Similarly, Jordanian females employed 24 occurrences more of "one expression of apology" than their male counterparts. Furthermore, American females used 30 times more "accounts as less explicit apology strategy" than their male counterparts. Meanwhile, Jordanian females also favored 10 times more accounts as their less explicit strategy than their male counterparts. The fact that females in both countries used more "one expression of apology" strategy and accounts than their male counterparts has helped corroborate the previous findings that women tend to apologize more often than males (as cited in Bataineh \& Bataineh, 2008).

It was also argued that gender differences existed and influenced the employment of apology strategies in British and Russian languages. The findings showed that compared to their male counterparts, British women used more direct apology strategies (i.e., 147 instances for females vs. 127 for males) coupled with more intensifiers (i.e., 184 times for females vs. 89 for males), more accounts (i.e., 320 instances for females vs. 285 for males). Resembling their British counterparts, Russian women appealed to more direct apology strategy (i.e., 150 for females vs. 139 for males), and more accounts (i.e., 326 for females vs. 281 for males) than Russian men. The Russian women particularly preferred the intensifying adverbial "objazatel'no", a Russian equivalent of "without fail" in English than their male counterparts (i.e., 26 instances for females vs. 14 for males). More interestingly, the British women (i.e., 5931 words in British female data vs. 5067 in British male data) and Russian women 
(i.e., 4094 words in Russian female data vs. 3536 in Russian male data) used longer linguistic forms or elaborate apologies than their male counterparts. The linguistic and strategic discrepancies of apology use between males and females in both languages lend support to the premise that gender affects language use to a certain extent (as cited in Bataineh \& Bataineh, 2008).

\subsection{Situational Variations in Apologies}

As indicated from the studies, a situationally dependent variable is another relevant factor held accountable for apology use. According to Bataineh \& Bataineh's study (2008), when it comes to the situation of bumping into somebody on the way to class and causing him/her to drop a load of books, both American and Jordanian respondents reacted to it by using more explicit strategy such as "one expression of apology" and by employing fewer accounts to explain the offense or the harmed situation. For the situation of breaking the promise to help a sister with her homework due to lack of time, they all agreed that no "self-criticism" as part of an account was worthy of employing. Also, under the situation of interrupting a friend when he or she is talking with his/her parent, both American and Jordanian respondents resorted to "one expression of apology" more often than indirect accounts indicating overall respect for their friends and their parents. Moreover, both American and Jordanian respondents offered no apology to the situation of staying out late without calling one's parents, which may reflect their mentality of pursuit for independence and they also did not apologize for the situation of waking up one's brother or sister by denying the offense or laughing off the incident or even blaming the victim (e.g., "If you were really sleeping, I would not have waken you up.") (Bataineh \& Bataineh, 2008).

Concerning perceptions of apologies, it is further suggested that in certain circumstances perceptions of apologies strongly depend on a situated discourse in which individuals have different interpretations of apology use. Influenced by various types of situations, perceptions of whether the offensive context threatens individual's positive or negative face have a certain effect on their intention to apologize (Park \& Guan, 2006). As exemplified in the study by Park and Guan (2006), the bus situation was regarded as a negative face threatened situation since the act of stepping on other person's foot is presumed to violate his/her personal space. The restaurant situation was characterized as a positive face threatened situation because the act of laughing at other person's belch is considered to embarrass him or her. Thus, regarding the perceptions of two situations within a language group, the study revealed that the Chinese participants were more inclined to perceive the threatening of others' positive face as an apology warranting situation (i.e., the restaurant situation). Conversely, U.S. students thought they would apologize when their behaviors threatened others' negative face (i.e., the bus situation). When comparing their perceptions of apology intention across two language groups, the researchers discovered that both Chinese and American participants considered a stronger intention to apologize when they perceived a conflict existing between in-group members (i.e., friends) rather than out-group members (i.e., strangers) in positive face threatened situations. Additionally, for the participants of both language groups, a similar level of perceptions of their intention to apologize both to a friend and a stranger was identified in negative face threatened situations.

\section{Conclusion}

The discussion so far has attested to the common sense that although the concept of apology is universal, its applications and interpretations can be divergent among various language groups and even within a language group (Park and Guan, 2006) in accordance with different sociocultural contexts, gender-related differences and situational characteristics. This observed sociolinguistic diversity in the speech act of apologizing has important implications for language teaching and learning since misunderstandings can easily arise if communicators across language groups fail to recognize those governing rules in different sociolinguistic contexts. For those learning or teaching a second/foreign language, the adjustment of apology strategies to sociolinguistic variations should be sensitized among L2 learners.

It is worth noting that because the four consulted empirical studies all recruited university undergraduates as their participants and their ages ranged from 19 to 24, the generalizability of their important findings begs the question of whether they are applicable to different age groups. It is reasonably suggested that future research should diversify age bands within a language group or across different language groups. In addition, gender-related differences remain controversial in apology studies, which calls for more scientific observations before more reliable conclusions can be drawn. Since the four empirical studies mainly used either discourse completion tests or questionnaires, new light could be shed on the apology use if different research instruments such as prompted production methods or corpus-based research can be adopted. To sum up, apology studies are expected to illuminate the understanding of sociolinguistic relativity if approached from multifaceted perspectives. 


\section{References}

Bataineh, Rula. F., \& Batainheh, Ruba, F. (2008). A cross-cultural comparison of apologies by native and speakers of American English and Jordanian. Journal of Pragmatics, 40, $792-821$. https://doi.org/10.1016/j.pragma.2008.01.003

Chang, W., \& Haugh, M. (2011). Evaluation of im/politeness of an intercultural apology. Intercultural Pragmatics, 8, 411-442. https://doi.org/10.1515/iprg.2011.019

Ogiermann, E. (2008). On the culture-specificity of linguistic gender differences: The case of English and Russian apologies. Intercultural Pragmatics, 5, 259-286. https://doi.org/10.1515/IPRG.2008.013

Park, H. S., \& Guan, X. (2006). The effects of national culture and face concerns on intention to apologize: a comparison of the USA and China. Journal of Intercultural Communication Research, 35, $183-204$. https://doi.org/10.1080/17475750601026933

Wolfson, N. (1989). Perspectives: Sociolinguistics and TESOL. New York: Newbury House Publishers.

\section{Copyrights}

Copyright for this article is retained by the author(s), with first publication rights granted to the journal.

This is an open-access article distributed under the terms and conditions of the Creative Commons Attribution license (http://creativecommons.org/licenses/by/4.0/). 